\title{
Intestinal absorption of bile salts
}

\author{
KAREN MADSEN, PHD
}

\begin{abstract}
Bile acids are secreted from the liver into the duodenum where they aid in the digestion and absorption of dietary lipids. Absorption of bile acids occurs through both ionic and nonionic diffusion in the jejunum and colon and through an active sodium ion-dependent carrier mechanism in the ileum. The primary bile acids synthesized in the liver can be converted by intestinal bacteria into secondary and tertiary bile acids. Bile acids may also be conjugated with glycine or taurine which results in an increase in the hydrophilicity and solubility of these compounds at physiological $\mathrm{pH}$. The amount of passive diffusion of bile acids that occurs across the brush border membrane along the length of the entire intestine depends upon the ratio of ionized to nonionized bile acids coupled with the bile salt concentration and the individual permeability coefficients of monomers. Active transport of both conjugated and nonconjugated species of bile acids depends upon the presence of a single negative charge on the side chain. Maximal transport rates for bile acids are related to the number of hydroxyl groups present while the Michaelis-Menten constant for transport is dependent upon whether or not the bile acid is conjugated. Although active uptake of bile acids from the ileum has been considered the major route for bile salt absorption in the small intestine, the mechanism may actually be responsible for only a small proportion of the total bile acid pool absorbed from the lumen. Can J Gastroenterol 1990;4(2):79-84
\end{abstract}

Key Words: Bile salts, Enterohepatic circulation

\section{Absorption intestinale des sels biliaires}

RESUME: Les acides biliaires sont sécrétés par le foie et déversés dans le duodénum où ils participent à l'absorption des lipides alimentaires. L'absorption des acides biliaires s'effectue par diffusion ionique et non-ionique dans le jéjunum et le côlon, et par l'intermédiaire d'un mécanisme de transport actif lié au $\mathrm{Na}^{+}$

Intestinal Disease Research Unit, Health Sciences Centre, University of Calgary, Calgary, Alberta

Correspondence and reprints: Dr KMadsen, Department of Pediatrics, Health Sciences Centre, 3330 Hospital Drive NW, Calgary, Alberta T2N 4N1. Telephone (403) 220-7370

Received for publication June 12, 1989. Accepted October 17, 1989
$\mathrm{T}$ HE SECRETION OF BILE FROM THE liver into the small intestine plays an important role in the efficient absorption of dietary lipids from the gut lumen. Bile is a complex mixture of bile acids, bile pigments, cholesterol, phospholipids, inorganic electrolytes and protein, which is secreted from the hepatocyte into the bile canaliculus and transported to the gallbladder for storage. Following ingestion of a meal, bile is released into the duodenum where bile acids aid in the digestion and absorption of dietary lipids. The bile acids are absorbed either by ionic or nonionic diffusion in the small intestine and colon (1), and via a process mediated by a sodium ion-dependent carrier in the terminal ileum (2). Although active absorption of bile acids by the ileum has traditionally been regarded as the main pathway of absorption, this mechanism may actually be responsible for only a small proportion of the total bile acid pool absorbed from the lumen. Following intestinal absorption, bile acids return to the liver via the portal vein, where more than $95 \%$ are removed on the first pass though the liver. This enterohepatic circulation allows for conservation of the bile acids. Only $10 \%$ of the total bile acid pool is 
et à l'oeuvre dans l'iléum. Les acides biliaires primaires synthétisés dans le foie peuvent être convertis en acides biliaires secondaires et tertiaires par des bactéries intestinales. Ils peuvent également se conjuguer avec le glycine ou la taurine, ce qui se traduit par l'hydrophilie et la solubilité accrues de ces composés au pH physiologique. Le degré de diffusion passive des acides biliaires qui se produit sur toute la longueur de l'intestin à travers la bordure en brosse, dépend du rapport entre les acides ionisés/non ionisés, ainsi que de la concentration des sels biliaires et des coefficients de perméabilité individuels des monomères. Le transport actif des types conjugués et non conjugués d'acides biliaires dépend de la présence d'une seule charge négative de la chaine latérale. Les taux maximaux de transport des acides biliaires sont liés au nombre de groupes hydroxyle présents alors que le $K_{n}$ varie selon que l'acide biliaire est conjugué ou pas. Bien que l'on ait estimé que le captage actif des acides biliaires dans l'iléon constitue le voie principale d'absorption des sels biliaires dans l'intestin grêle, il se pourrait que le mécanisme ne soit en fait responsable que d'un petit pourcentage de la quantité totale du pool des acides biliaires absorbés à partir de la lumière.

lost in the feces per day. This daily loss is balanced by hepatic synthesis of new bile acids from cholesterol. The total bile acid pool in humans is 3 to $5 \mathrm{~g}$, which circulates six to 10 times every day, resulting in over $18 \mathrm{~g}$ of bile acids entering the gut per day (3).

\section{PHYSIOLOGICAL ROLE}

Bile salts consist of a steroid hydrophobic nucleus with hydrophilic hydroxyl and amide linkages. At a concentration range of 0.6 to $10 \mathrm{mM}$ (the critical micellar concentration), bile salt molecules aggregate with their hydrophobic sides together forming micelles (4). In this way, bile salt micelles can make soluble molecules that are otherwise water insoluble, eg, cholesterol, lecithin, lipovitamins and monoglycerides, to form mixed micelles (4). The critical micellar concentration varies depending on the individual bile salts present, temperature, $\mathrm{pH}$, presence or absence of lipids, and ionic concentration of the solution (5). Above the critical micellar concentration, bile salt monomers and micelles exhibit an equilibrium, with the monomeric concentration not exceeding the critical micellar concentration (5).

Bile salt micelles form a one-to-one complex with colipase (6). In turn, colipase binds to lipase in a one-to-one ratio (6). This binding interaction of micelles to colipase to lipase serves to facilitate removal of the lipolytic end products into the mixed micelles and prevent feedback inhibition of hydrolysis (7). Mixed micelles consisting of fatty acids, monoglycerides, lecithin, lysolecithin, diglyceride, cholesterol and bile salts pass through the unstirred water layers to enterocytes where the digestion products passively enter the epithelial cell (8).

Bile secretion also provides a mechanism for the excretion of cholesterol and exogenous drugs (9). Not only are bile acids continually synthesized from cholesterol, but conjugated bile salts make cholesterol and lecithins soluble in mixed micelles (10). The secretion of these mixed micelles in bile provides for loss of cholesterol in feces. metabolism

\section{CHEMISTRY OF BILE ACIDS}

Bile acids consist of a family of molecules formed from cholesterol (Figure 1). Two of the bile salts, known as primary bile salts, are synthesized in the liver in humans - cholic acid and chenodeoxycholic acid (11). Intestinal bacteria are able to convert primary bile acids into secondary and tertiary bile acids via three major mechanisms: deconjugation (thereby releasing unconjugated bile acids); 7-dehydroxylation converting cholic acid to deoxycholic acid and chenodeoxycholic acid to lithocholic acid; and 7. dehydrogenation converting cheno. deoxycholate to 7-oxolithocholate, which can be epimerized to urso. deoxycholate (12). While bile normally contains only very small amounts of secondary and tertiary bile acids ( less than 2 to $5 \mathrm{M}$ ), feces and urine contain a large number of different forms of bile acids $(13,14)$. This is mainly due to the inefficient absorption of uncommon bile acids from the colon (where most are produced by bacterial action) and the efficient conversion of uncommon bile acids to common forms by reduc. tion, hydroxylation, and epimerization in the liver (15).

After synthesis, bile acids are con. jugated with glycine or taurine via the $\mathrm{C}_{5}$ branched side chain (16). Conjugation serves to increase the hydro.

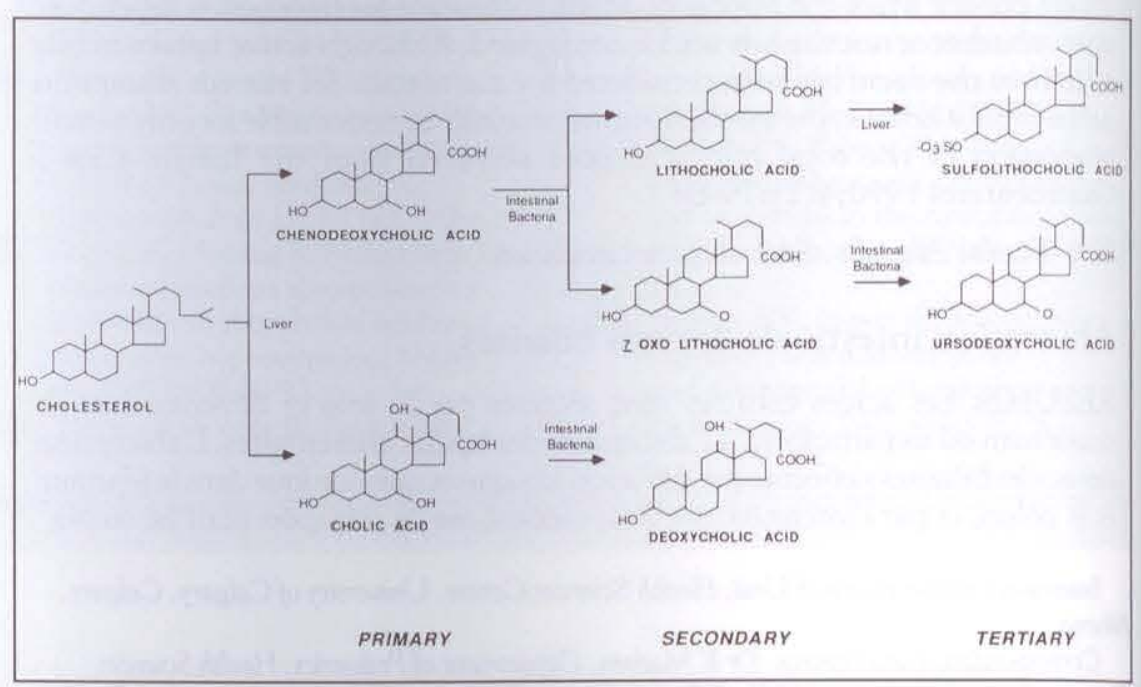

Figure 1) Primary, secondary and tertiary bile salts of humans showing sites of synthesis and 
philicity and solubility of bile acids at physiological $\mathrm{pH}$, thereby decreasing their ability to cross plasma membranes (16). Taurine conjugates $\left(\mathrm{pK}_{\mathrm{a}} 2.0\right)$ are more water soluble than are glycine conjugates ( $\mathrm{pK}_{\mathrm{a}} 3$ to 4 ) and generally trihydroxy bile salts are more water soluble than are dihydroxy bile salts (12). At physiological $\mathrm{pH}$, taurine and glycine conjugates are completely ionized and water soluble, leading to the term 'bile salt'. 'Bile acids' generally refer to undissociated bile salts, conjugated or unconjugated, that are only mildly water soluble. Bile acids and salts differ in several of their physicochemical properties, resulting in different transport properties (17).

\section{INTESTINAL ABSORPTION OF BILE ACIDS AND SALTS}

Bile salts differ greatly in polarity and have at least three physiological routes of the enterohepatic circulation that differ in rate, location, and species transported. These include the jejunal passive route (fast), the ileal active and passive routes (intermediate), and the colonic passive route (slow). A large percentage of glycine-conjugated dihydroxy bile acids are absorbed passively in the jejunum $(18,19)$, while taurine and glycine conjugates of the dihydroxy and trihydroxy bile salts are absorbed actively in the ileum $(1,18)$ and unconjugated bile acids are absorbed from the colon $(1,20)$.

Passive diffusion: Bile acids, both conjugated and unconjugated, are absorbed passively at all levels of the intestine. This passive movement is characterized by movement down existing concentration gradients (lumen to portal blood); an increasing concentration of bile acids resulting in increased absorption; no saturation kinetics; no competitive inhibition between bile acids; and no effect of metabolic inhibitors on absorption (1).

There are two barriers which have to be crossed in order for the bile acid to enter the enterocyte - these are the unstirred water layer and the brush border membrane. Either one of these may be rate limiting.

Size and weight are two main factors that influence the rate of diffusion through the unstirred water layer, the diffusion coefficient being inversely proportional to size (21). For this reason, micelles exhibit a much slower rate of diffusion through the unstirred water layer than do bile salt monomers, resulting in a slower rate of uptake from higher concentrations (greater than the critical micellar concentration) of bile acids (22). However, because micelles and ionized and nonionized monomers are in equilibrium with each other above the critical micellar concentration, all three species will diffuse independently through the water layer and contribute to total absorption (23).

The acidic microclimate ( $\mathrm{pH} 5.1$ to 6.3) that exists at the surface of the enterocytes (23) will also affect uptake of bile acids, as it is the luminal pH which determines the proportion of bile acids in ionized or nonionized form. Also, micelles have been shown to dissociate at a pH of 5 to 6 (24). The acidic microclimate would therefore favour micelle dissociation and the release of monomers to the epithelial surface for absorption.

In general, it is the ratio of ionized to nonionized bile acids, as determined by intraluminal $\mathrm{pH}$, coupled with the bile salt concentration and individual permeability coefficients of monomers, that will affect the relative proportion of bile acids absorbed passively.

Passive nonionic diffusion: In the lumen of the small intestine, the $\mathrm{pH}$ varies from 5.5 to 6.5 , causing about $50 \%$ of unconjugated bile salts $\left(\mathrm{pK}_{\mathrm{a}} 5\right.$ to 6.5 ) to be nonionized, while a very small percentage of the glycine-conjugated bile salts ( $\mathrm{pK}_{\mathrm{a}} 3.5$ to 5.2) and no taurine-conjugated bile salts $\left(\mathrm{pK}_{\mathrm{a}}\right.$ less than 1) are nonionized. Under normal physiological conditions, only conjugated bile salts are present in the jejunum (25). Therefore, the major bile acids absorbed in the jejunum are glycine conjugates. However, deconjugation of bile salts occurs to a large extent in the terminal ileum and colon, and colonic passive absorption of unconjugated bile acids occurs continuously throughout the day (26). Nonionized species can readily diffuse through epithelial cell membranes driven by a concentration gradient only. The rate of diffusion of bile acids across membranes has been found to be dependent on the number of hydroxyl groups present and the size of the group conjugated at $\mathrm{C}_{24}$ (27). The passive permeability coefficients of monomers have been shown to decrease by factors of $3.4,6.8$ and 8.1 , with the addition of a hydroxyl, glycine, or taurine, respectively (1). Therefore, for nonionized bile acids, diffusion through the unstirred water layer becomes rate limiting, especially for micelle solutions (28). Bile acid absorption from the micelle at the membrane is believed to occur only for monomers present in the aqueous phase that are in equilibrium with their aggregates within the micelle (28). There is no evidence that the entire micelle is taken up intact by the cell membrane (22).

Ionized diffusion: The driving force for ionized diffusion is the electrochemical gradient across the membrane. However, biological membranes are relatively impermeable to charged molecules; therefore, the diffusion rate of negatively charged conjugated bile acids is very low (29). Based on an intraluminal activity of $1 \mathrm{mM}$, ionized bile salts will theoretically passively diffuse at the rate of $400 \mathrm{nmol} / \mathrm{min} / \mathrm{cm}$ gut, compared to nonionized movement of $2000 \mathrm{nmol} / \mathrm{min} / \mathrm{cm}$ gut (30). Further evidence to support a low rate of diffusion for ionized bile salts comes from nuclear magnetic resonance spectroscopy studies. These have shown that at a high $\mathrm{pH}$ (when bile acids are ionized), there is no appreciable movement of cholic acid, chenodeoxycholic acid or deoxycholic acid across a model bilayer membrane (31). However, following protonation, a rapid equilibrium between the inner and outer monolayers of the membrane was observed (31). The presence of more than one type of bile acid in the same bilayer membrane was found to have no effect on the movement of any other type (31).

The relative contribution of ionic versus nonionic diffusion will depend on the intraluminal $\mathrm{pH}$, the $\mathrm{pK}_{\mathrm{a}}$ of the bile acid, and the permeability and partition coefficients of the ionic and nonionic species.

Active transport of bile acids: Bile salts 
are transported in the ileum via a sodium ion-dependent bile acid cotransport system (29). Energy for active transport is provided by the extracellular to intracellular sodium ion gradient across the brush border membrane, that is maintained by $\mathrm{Na}^{+},-\mathrm{K}^{+}$-ATPase activity on the basolateral membrane. Active transport is evidenced by the following observations: absorption can occur against a concentration gradient $(32,33)$; absorption is blocked by metabolic inhibitors or anaerobiosis $(29,32)$; absorption of bile acids follows saturation kinetics $(18,32,34)$; individual bile acids inhibit absorption of other bile acids (18); absorption is dependent on the presence of sodium ions $(33,35,36)$; and transport can occur when transmural potential difference is zero (37).

All naturally occurring bile salts have been shown to be actively transported (38). There appears to be no absolute requirement for the presence of a hydroxyl group for a bile salt to be transported (38). However, while both conjugated and nonconjugated species are transported, a single negative charge on the side chain is required (38). The presence of two negative charges results in very limited transport, and the introduction of a positive charge onto the substrate results in no transport at all (38). These structure-activity studies indicate that the initial recognition site for bile acid transport must involve three elements: interaction between the sterol nucleus of the bile acid and the carrier; a coulombic interaction between the negatively charged side chain and a positively charged site on the transporter; and interaction between sodium ions and an anionic site on the transporter $(35,39)$.

Photoaffinity labelling of jejunal and ileal brush border membrane vesicles with photolabile bile salt derivatives identified a 99,000 dalton polypeptide that was unique to the ileum, leading to the supposition that it is this protein that is the sodium iondependent bile salt transporter (40). This 99,000 dalton protein is also labelled in the proximal tubules of the rat kidney (11) - an area that exhibits similar sodium ion-dependent bile salt transport (28), but not in liver (41), another site of sodium ion-dependent bile salt uptake (42). These studies suggest that a single membrane protein is involved in both renal and ileal bile salt cotransport, and that sodium ion-dependent transport across the sinusoidal membrane of hepatocytes is mediated by a different membrane protein.

Several studies with brush border membrane vesicles have demonstrated that bile acid uptake is sodium ion specific $(32,35)$. However, conflicting data exists as to whether or not sodium ion-dependent bile salt transport is electroneutral (43) or electrogenic $(36,44)$. While Lucke et al $(36)$ and Wilson et al (44) observed a relationship between various diffusion potentials across brush border membrane vesicles and the rate of sodium ion-dependent taurocholate uptake, Rouse et al (43) showed no effect of interchanging chloride, thiocyanate, or sulphate ions. Further studies will have to be done to determine clearly whether sodium ion-dependent bile salt transport is electrogenic or electroneutral.

The Michaelis-Menten constant $\left(K_{m}\right)$ of bile acid transport appears to be related to whether or not the bile acid is conjugated, as unconjugated species show a higher $\mathrm{K}_{\mathrm{m}}$ than do glycine or taurine conjugates (45). However, maximum transport rates $\left(\mathrm{J}_{\mathrm{m}}\right)$ are independent of conjugation, but instead are related to the number of hydroxyl groups (trihydroxyl $>$ dihydroxyl $>$ monohydroxyl) (45). It appears at this point that a single species of bile transporter in the small intestine is responsible for the transport of all bile acids. This is evidenced by the inhibition kinetics exhibited between different pairs of bile acids (46).

\section{CONTRIBUTION OF PASSIVE VERSUS ACTIVE TRANSPORT}

The active uptake of bile salts from the ileum has been considered quantitatively to be the major mechanism for bile salt absorption from the small intestine. This concept has arisen from several different studies. First, the concentration of bile salts is maintained throughout the jejunum, and only begins to fall in the distal ileum (29). Second, resection of the terminal ileum $(47,48)$ but not the jejunum $(47)$ results in extensive fecal bile salt loss. Finally, an efficient active transport mechanism operates in the ileum only (44).

The report by Dietschy (29) that bile salt concentration does not fall except in the terminal ileum does not necessarily mean that bile salt absorption has not occurred. Changes in the volume of luminal contents by absorption of water will affect concentration measurements. If the concentration of bile salts remains constant when water is being absorbed, absorption of bile salts must be occurring concomitantly. If not, the bile concentration would increase.

Resection of the terminal ileum often involves removal of the ileocecal valve, allowing colonic bacteria to migrate proximally (49). Greater colonization of bacteria may result in greater bile salt loss due to an increase in deconjugation of bile salts.

With extensive passive absorption of bile acids occurring in the jejunum, it would be expected that a lower concentration of bile acids would reach the ileum. Therefore, an efficient active transport system occurring at low concentrations would be necessary in the ileum in order to conserve effectively any remaining bile acids after jejunal passage. Studies that have shown distal absorption as outweighing proximal absorption have used low concentrations of bile salts, for which the active ileal pump would be expected to dominate (24).

McClintock and Shiau (24), using kinetic data derived from taurocholate active transport in the rat, calculated that active ileal absorption was not sufficient to recover the percentage of bile salts secreted. Passive absorption was shown to account for the majority of total bile salt conservation. Passive absorption was also shown to account for a significant portion of bile salt uptake in the pig (50) and the killifish (34), supporting the view that it is the passive jejunal uptake of bile acids that is of most importance quantitatively in bile salt conservation. Also, Dowling et al (51) have demonstrated that ileectomized monkeys are able to reabsorb from 38 to $58 \%$ of the bile salts entering 
the small intestine, suggesting a large quantitative role for the jejunum in bile salt conservation.

It therefore appears that while the distal ileum is more efficient at absorb. ing bile salts due to the presence of a sodium ion-dependent active transport mechanism, passive absorption accounts for a significant amount of bile salt uptake. The presence of an active transport function in the ileum probably represents a mechanism for salvaging any bile salts not absorbed in the jejunum and preventing their entry into the colon under normal conditions. Passive transport in the colon would further act to salvage bile salts that escape jejunal and ileal uptake mechanisms.

Javitt N. Bile salt patterns in portal vein blood. Gastroenterology 1971;60:761. (Abst)

27. Dupas J, Hoffman A. Passive jejunal absorption of bile acids in vivo: Struc ture activity relationships and rate limiting steps. Gastroenterology 1984;86:1067. (Abst)

28. Wilson G, Burckhardt G, Murer H, Runrich G, Ullrich K. Sodium coupled taurocholate transport in the proximal convolution of the rat kidney in vivo and in vitro. J Clin Invest 1981;67:1141-50.

29. Dietschy J. Mechanisms for the intestinal absorption of bile acids. J Lipid Res 1968;9:297-309.

30. Dietschy ]. Effects of bile salts on intermediate metabolism of the intestinal mucosa. Fed Proc 1967;26:1589-97.

31. Cabral E, Small D. Transbilayer movement of bile acids in model membranes. Biochemistry 1987;26:1801-4.

32. Lack L, Weiner I. In vitro absorption of bile salts by small intestine of rats and guinea pigs. Am J Physiol 1961;200:313.

33. Holt $P$. Intestinal absorption of bile salts in the rat. Am J Physiol 1964;207:1.

34. Honkanen R, Patten J. Bile salt absorption in killifish intestine. Am J Physiol 1987;253:G730-6.

35. Gallagher K, Mauskopf J, Walker J, Lack L. Ionic requirements for the active bile salt transport system. J Lipid Res 1976;17:572-7.

36. Lucke H, Strange G, Kinne R, Murer $\mathrm{H}$. Taurocholate sodium cotransport by brush border membrane vesicles isolated from rat ileum. Biochem ] 1978;174:951-8.

37. Dietschy J, Solomon H, Siperstein M. Bile acid metabolism. J Clin Invest 1966;45:832.

38. Tyor M, Gorbutt ], Lack L. Metabolism and transport of bile salts in the intestine. Am J Med 1971;51:614-26.

39. Bundy R, Mauskopf J, Walker T, Lack L. Interaction of uncharged bile salt derivatives with the ileal bile salt transport system. J Lipid Res 1977; 18:389-95.

40. Kramer W, Burckhardt G, Wilson F, Kurz G. Bile salt binding polypeptides in brush border membrane vesicles from the rat small intestine revealed by 
photaffinity labelling. J Biol Chem 1983;258:3623-7.

41. Ziegler K. Further characterization of $3^{\prime}$ isothiocyanate benzamido $\left(\mathrm{H}^{3}\right)$ cholate binding to hepatocytes. Correlation with bile acid transport inhibition and protection by substrates and inhibitors. Biochim Biophys Acta 1985;819:37-44.

42. Inoue M, Kinne R, Tran T, Arias I. Taurocholate transport by rat liver sinusoidal membrane vesicles: Evidence of sodium cotransport. Hepatology 1982;2:572-9.

43. Rouse D, Lack L. Ion requirements for taurocholate transport by ileal brush border membrane vesicles. Life Sci 1979;25:45-52.
44. Wilson F, Treannor L. Glycodeoxycholate transport in brush border membrane vesicles isloated from rat jejunum and ileum. Biochim Biophys Acta 1979;554:430-40.

45. Ho N. Utilizing bile acid carrier mechanisms to enhance liver and small intestine absorption. Ann NY Acad Sci 1987;507:315-29.

46. Holt P. Competive inhibition of intestinal bile salt absorption in the rat. Am J Physiol 1966;210:635.

47. Playoust M, Lack L, Winer I. Effect of intestinal resection on bile salt absorption in dogs. Am J Physiol 1965;208:363-9.

48. Hofmann A, Roley A. Role of bile acid malabsorption in pathogenesis of diar- rhea and steatorrhea in patients with ileal resection. Gastroenterology 1972;62:918-34.

49. Hofmann A. The relationship between uptake in vitro of oleic acid and micellar solubilization. Biochim Biophys Acta 1970;196:193-203.

50. Juste $\mathrm{C}$, Legrand-Defretin V, Coring $\mathrm{T}$, Rerat A. Intestinal absorption of bile acids in the pig. Role of distal bowel. Dig Dis Sci 1988;33:67-73.

51. Dowling R, Eberhard M, Small D. Effects of controlled interruption of the enterohepatic circulation of bile salts by biliary diversion and by ileal resection on bile salt secretion, synthesis and pool size in the Rhesus monkey. J Clin Invest 1970;49:232-42. 


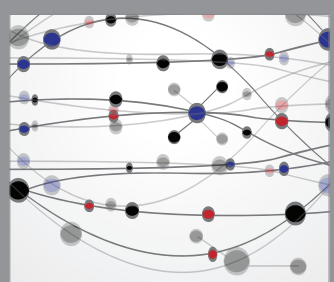

The Scientific World Journal
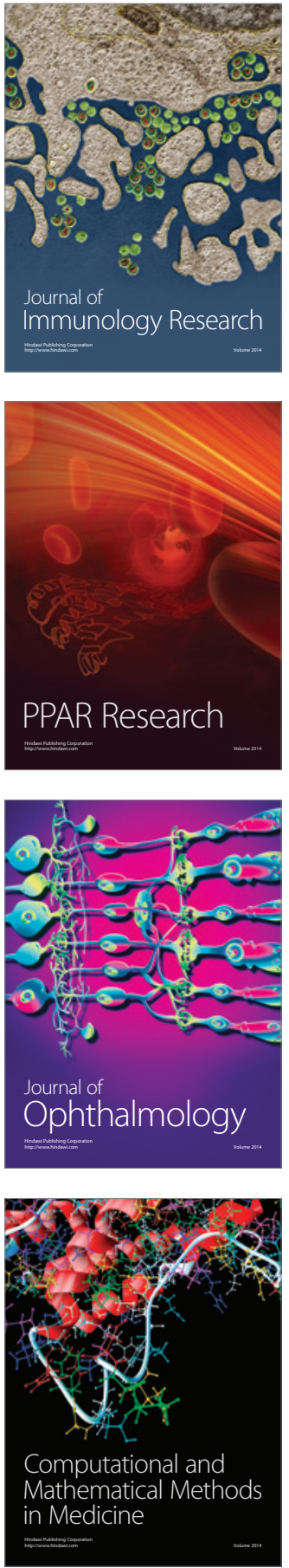

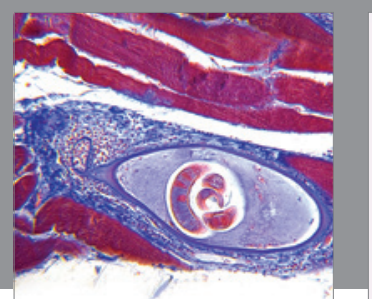

Gastroenterology Research and Practice

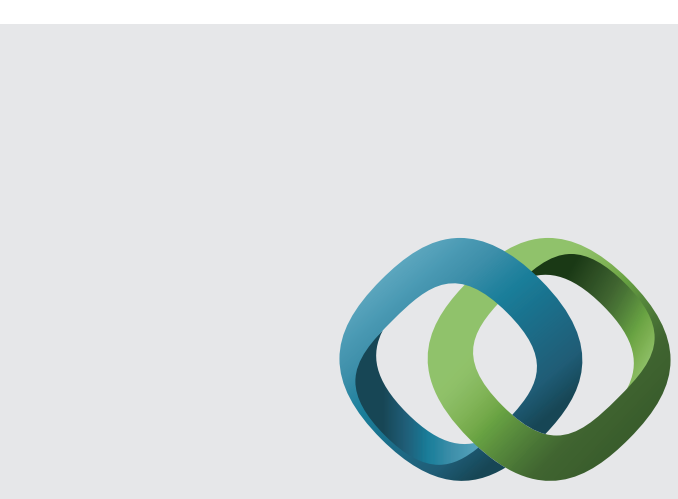

\section{Hindawi}

Submit your manuscripts at

http://www.hindawi.com
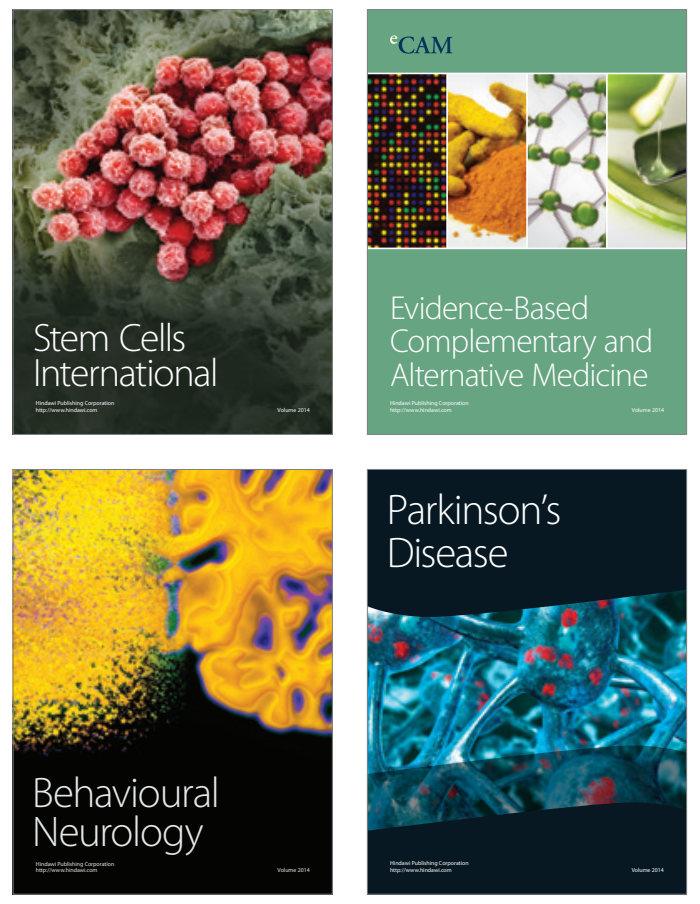
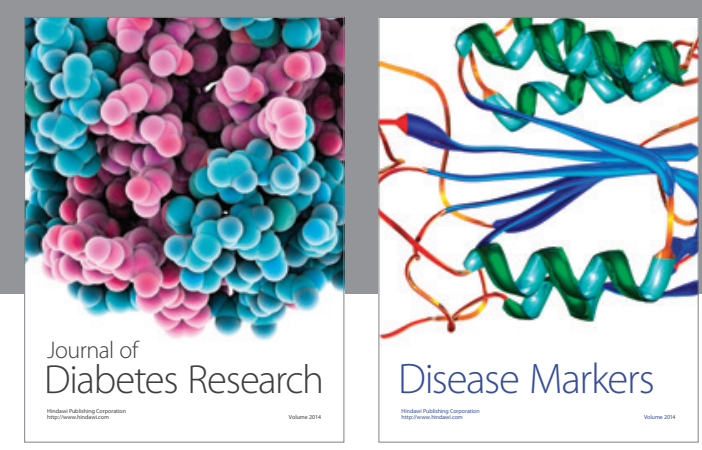

Disease Markers
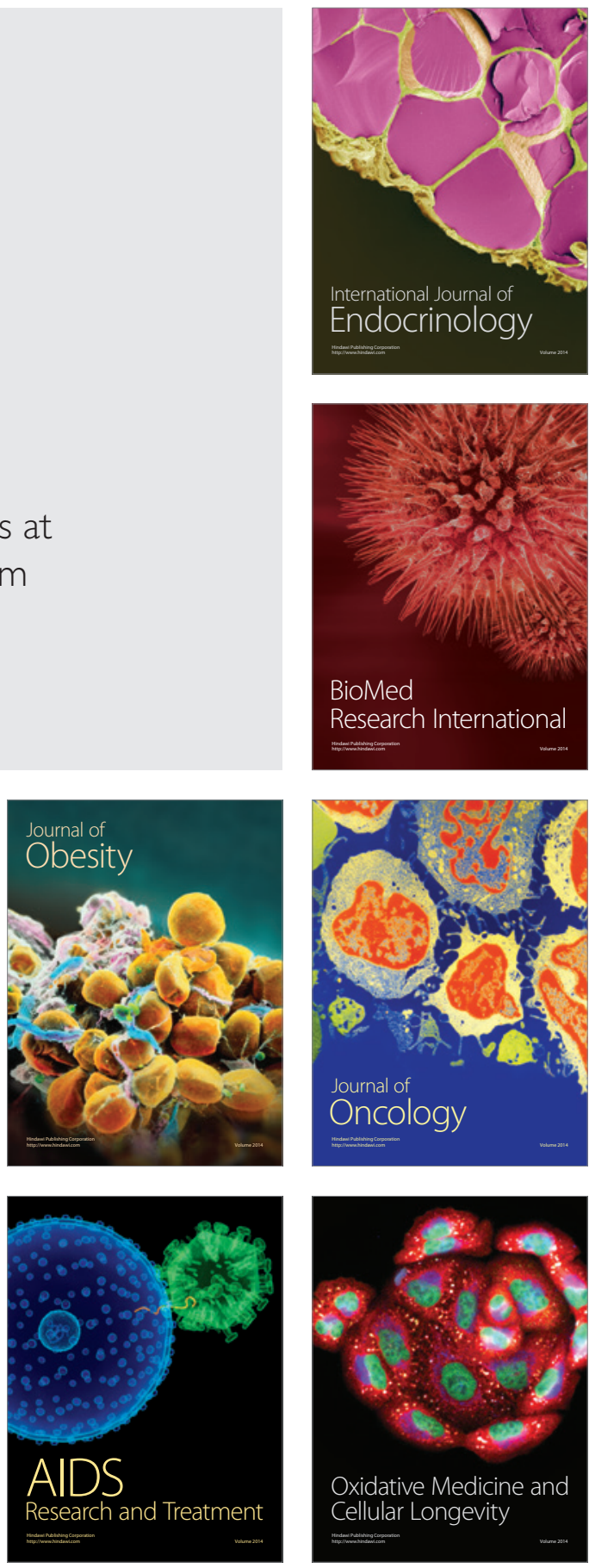